\title{
Association between diabetes, severe hypoglycaemia, and electroencephalographic abnormalities
}

\author{
G SOLTÉSZ AND G ACSÁDI
}

Department of Paediatrics, University of Pécs, Hungary

SUMMARY Serial electroencephalographic recordings were made in 70 diabetic children and findings were related to age at electroencephalography and at diagnosis, duration of diabetes, daily insulin dose, long term metabolic control assessed by glycated haemoglobin $\mathrm{A}_{1}\left(\mathrm{HbA}_{1}\right)$ concentrations, and severe hypoglycaemic episodes. Abnormalities were found in $18(26 \%)$ of diabetic children, and in only five $(7 \%)$ of control subjects. There were no associations between electroencephalographic abnormalities and duration of diabetes, daily insulin dose, or $\mathrm{HbA}_{1}$ concentration. Diabetic children with electroencephalographic abnormalities were younger, had an earlier onset of diabetes and $21 / 34(62 \%)$ of them had previously severe attacks of hypoglycaemia, whereas abnormalities were found in only $13 / 43(30 \%)$ of diabetic children who had not had severe hypoglycaemia. All diabetic children with hypoglycaemic convulsions had permanent electroencephalographic abnormalities. The degree of metabolic control had no effect on the electroencephalographic findings during the early years of diabetes, but previous severe hypoglycaemia, young age, and early onset seem to be important risk factors for electroencephalographic abnormalities.

Prolonged and recurrent hypoglycaemia can cause permanent brain damage ${ }^{1}$ and the brains of infants and children appear to have an increased vulnerability to hypoglycaemia. ${ }^{2}$ Hypoglycaemia induced by exogenous insulin injection in diabetes mellitus is the commonest form of hypoglycaemia in children. It is important therefore, to assess the possible effect of hypoglycaemia on the brain of diabetic children. Furthermore other metabolic abnormalities of diabetes - for example, chronic hyperglycaemia and ketosis-could also have a harmful effect on the central nervous system.

Several studies of electroencephalograms in diabetic children have been published, ${ }^{3-8}$ which tried to find an association between electroencephalographic features and hypoglycaemia, as well as to correlate these abnormalities with diabetic control and microvascular complications among other things. Almost all of these observations were reported 15 to 20 years ago, however, and only scarce reports are available for the last decade during which important changes have taken place in the management of diabetic children-for example, the introduction of new insulins and insulin delivery devices, and better methods for assessment of metabolic control.

At least two of these developments make it necessary to look again at the electrophysiological abnormalities in diabetic children. Firstly, with regular measurements of stable glycated haemoglobin $\mathrm{A}_{1}\left(\mathrm{HbA}_{1}\right)$ concentrations it is now possible to assess objectively the degree of long term metabolic control and relate it to the electroencephalographic changes. Secondly, the introduction of new methods of intensified insulin treatment is likely to increase the incidence of hypoglycaemia, and the risk of hypoglycaemic brain damage may also increase. For the future assessment of this possibly increasing risk, therefore, it is essential to have information on the frequency of severe hypoglycaemic attacks as well as on the extent of hypoglycaemia related electroencephalographic abnormalities under the present diabetic $N$ management before increasing the use and availability of intensive insulin treatment.

The aim of this study was to analyse the influence of various factors on the electroencephalographic pattern in diabetic children with particular reference to long term metabolic control and previous attacks of severe hypoglycaemia.

\section{Patients and methods}

Seventy diabetic children, 37 girls and 33 boys, 
mean (SEM) age $11.2(0 \cdot 5)$ years, and duration of diabetes $5.0(0.4)$ years, participated in the study. None of them had any perinatal diseases, a personal or family history of epilepsy, or neurological symptoms. All children were followed up in our diabetic clinic using the same principles of insulin and dietary treatment, which included twice daily injections of short and intermediate acting insulin and restricted carbohydrate diet. Metabolic control was assessed by regular (three to five times a year) measurements of $\mathrm{HbA}_{1}$ concentrations. None of the children had albuminuria, retinopathy, or arthropathy.

The case notes of all children were carefully studied retrospectively, and every severe hypoglycaemic episode was recorded (defined as loss of consciousness or convulsions, or both, requiring the assistance of a second person). The retrospective diagnosis of hypoglycaemia was based on the clinical symptoms and on the effect of parenteral glucagon. Blood glucose was measured in only five cases (mean $1.9 \mathrm{mmol} / \mathrm{l}$ ). Mild and moderate hypoglycaemic episodes occurred in all children with variable frequency. As neither the parents nor the children were able to give a reliable record of these events the episodes were not evaluated.

At the time of the study, the children were in good general condition with blood glucose concentrations between 6 and $14 \mathrm{mmol} / \mathrm{l}$. Electroencephalographic recordings were carried out with an eight channel electroencephalograph using the 10-20 international system. Recording at rest (usually in the afternoon) lasted for at least 20 minutes including hyperventilation. In children with previous hypoglycaemic episode(s), the electroencephalogram was recorded at least one month after the hypoglycaemic episode (mean (SEM) 25 (5), range 2-96 months). If an abnormality was found, the recording was repeated after a mean period of 15 (2) months. The electroencephalogram of age matched (mean age $10.9(0.41)$ years) normal controls (37 girls and 33 boys) were also assessed by the same investigator without knowledge of their clinical state. The electroencephalogram was analysed visually by one of us (GA) who had no information of the children's clinical and laboratory data. Recordings were classified according to the following scale taking into account the characteristic age dependent changes as suggested by Haumont et a $\vec{l}^{5}$ and Tsuboi. ${ }^{9}$ Grade 1: Normal background activity. Grade 2: Borderline disease: irregular basic rhythm with marked excess of slow waves or synchronisation. Grade 3: Asymmetry on background activity, small sharp waves or moderate to severe 'slow down' effects of hyperventilation. Grade 4: Paroxysmal pattern: spike waves. Grade 5: Paroxysmal pattern: spike groups.

For the statistical analysis of the data Student's $t$ test and the $\chi^{2}$ test were used.

\section{Results}

Abnormal electroencephalogram patterns (grades 2 to 5) were found in $34(49 \%)$ of the diabetic children compared with $17(24 \%)$ of the controls $(p<0 \cdot 05)$. If only grade 3 to 5 abnormalities were considered, 18 children $(26 \%)$ had abnormal electroencephalograms, still a high figure considering that these abnormalities were found in only five $(7 \%)$ of the 70 normal, healthy children $(\mathrm{p}<0 \cdot 01)$. Table 1 shows that, in contrast to the controls, diabetic children with abnormal electroencephalogram were significantly younger $(p<0 \cdot 01)$. Diabetic children with electroencephalogram abnormalities also had earlier onset of diabetes. There was, however, no significant difference between those with normal and abnormal electroencephalograms in the duration of diabetes, mean daily insulin dose, or mean $\mathrm{HbA}_{1}$ concentrations (mean of the last five years).

The incidence of electroencephalographic abnormalities, however, was significantly higher in those

Table 1 The association between abnormal electroencephalogram and age, duration of diabetes, daily insulin dose, and $H b A_{1}$ concentration. Values are expressed as mean (SEM)

\begin{tabular}{|c|c|c|c|c|c|c|}
\hline & \multicolumn{2}{|c|}{$\begin{array}{l}\text { Age at electro- } \\
\text { encephalogram (years) }\end{array}$} & \multirow{2}{*}{$\begin{array}{l}\text { Age at } \\
\text { diagnosis } \\
\text { (years) }\end{array}$} & \multirow{2}{*}{$\begin{array}{l}\text { Duration of } \\
\text { diabetes } \\
\text { (years) }\end{array}$} & \multirow[t]{2}{*}{$\begin{array}{l}\text { Daily insulin } \\
\text { dose (U/kg) }\end{array}$} & \multirow{2}{*}{$\begin{array}{l}H b A_{1} \\
\text { concentration } \\
(\%)\end{array}$} \\
\hline & $\begin{array}{l}\text { Control } \\
\text { subjects }\end{array}$ & Diabetics & & & & \\
\hline $\begin{array}{l}\text { Normal } \\
\text { electroencephalogram }\end{array}$ & $\begin{array}{l}10 \cdot 3(1 \cdot 7) \\
(n=53)\end{array}$ & $\begin{array}{l}12 \cdot 8(0 \cdot 7) \\
(n=36)\end{array}$ & $7 \cdot 6(0 \cdot 6)$ & $5 \cdot 8(0 \cdot 6)$ & $0.97(0.05)$ & $11 \cdot 3(0 \cdot 2)$ \\
\hline $\begin{array}{l}\text { Abnormal } \\
\text { electroencephalogram }\end{array}$ & $\begin{array}{l}10 \cdot 5(2 \cdot 8) \\
(n=17)\end{array}$ & $\begin{array}{l}9 \cdot 6(0 \cdot 7) \\
(n=34)\end{array}$ & $4 \cdot 8(0 \cdot 6)$ & $4.5(0.6)$ & $0.85(0.07)$ & $11 \cdot 4(0 \cdot 2)$ \\
\hline p Value & $>0.5$ & $<0.01$ & $<0.01$ & $0 \cdot 1$ & $0 \cdot 1$ & $>0.5$ \\
\hline
\end{tabular}


children who had a history of one or more severe hypoglycaemic episodes compared with those who had no such episodes (table 2$)(\mathrm{p}<0 \cdot 001)$. Almost $80 \%$ of the children with previous severe hypoglycaemia had abnormal electroencephalograms, whereas abnormalities could be detected in only $30 \%$ of the non-hypoglycaemic group (table 2 ). In other words, only $22 \%$ hypoglycaemic children had normal electroencephalograms as opposed to $77 \%$ of those without previous severe hypoglycaemia $(p<0 \cdot 001)$. Table 2 also shows that only six out of 36 children $(17 \%)$ with normal electroencephalograms had severe hypoglycaemia, whereas 21 out of 34 children $(62 \%)$ with abnormal electroencephalograms had hypoglycaemic episode(s) $(\mathrm{p}<0.001)$.

The grading of abnormalities (table 3 ) shows even

Table 2 The association between electroencephalographic abnormalities and previous hypoglycaemia

\begin{tabular}{lll}
\hline & $\begin{array}{l}\text { No with } \\
\text { hypoglycaemic } \\
\text { episodes }\end{array}$ & $\begin{array}{l}\text { No without } \\
\text { hypoglycaemia }\end{array}$ \\
\hline $\begin{array}{c}\text { Normal electro- } \\
\text { encephalogram }\end{array}$ & 6 & 30 \\
$\begin{array}{c}\text { Abnormal electro- } \\
\text { encephalogram }\end{array}$ & 21 & 13 \\
\hline
\end{tabular}

$\chi^{2}=14.75, p<0.001$.

Table 3 Electroencephalographic abnormalities in diabetic children

\begin{tabular}{lll}
\hline $\begin{array}{l}\text { Abnormal } \\
\text { electroencephalogram }\end{array}$ & $\begin{array}{l}\text { No with } \\
\text { hypoglycaemic } \\
\text { episodes }\end{array}$ & $\begin{array}{l}\text { No without } \\
\text { hypoglycaemic }\end{array}$ \\
\hline Grade 2 & 7 & 9 \\
Grade 3 & 9 & 4 \\
Grade 4 & 3 & 0 \\
Grade 5 & 2 & 0 \\
\hline Total & 21 & 13 \\
\hline
\end{tabular}

more clearly the effect of hypoglycaemia. Fourteen out of the 21 hypoglycaemic children with abnormal electroencephalograms $(67 \%)$ had grade 3 to 5 abnormalities, whereas most non-hypoglycaemic diabetics in this 'abnormal electroencephalogram' group had only borderline abnormalities (grade 2) and none had grade 4 to 5 abnormalities. If only grade 3 to 5 findings are considered, our data show a fivefold increase in the incidence of electroencephalographic abnormalities in the hypoglycaemic group (14 out of 27 children) compared with the nonhypoglycaemic group (four out of 43 children). In comparison, no control children had grade 5 abnormalities, and only one had a grade 4 abnormality. The finding that all the 11 children who had hypoglycaemic convulsions had abnormal electroencephalograms further emphasises the association between hypoglycaemia and electroencephalographic abnormalities.

Eight of the 27 children in the hypoglycaemic group had two or more severe episodes. Altogether 37 severe hypoglycaemic episodes occurred in the 27 children, which gives an incidence rate of 0.28 episodes/patient year for the 'hypoglycaemic group' and a rate of 0.12 episodes/patient year for the whole group. It is interesting to note that the electroencephalogram was negative in only one of the eight children with repeated severe attacks of hypoglycaemia.

In 21 of the 27 children with hypoglycaemia, recordings were repeated after a mean period of 15 (2) months. The same degree of abnormality was found in 15 cases, the electroencephalogram remained normal in four cases, and a previously unrecorded abnormality developed in two cases.

Finally, in an attempt to identify risk factors for hypoglycaemia, table 4 shows that the mean age at diagnosis, duration of diabetes, daily insulin dose, and $\mathrm{HbA}_{1}$ concentrations were not significantly different in the hypoglycaemic and non-hypoglycaemic groups, but hypoglycaemic children were significantly younger.

Table 4 Clinical data of diabetic children with and without hypoglycaemic episodes. Values are expressed as mean (SEM)

\begin{tabular}{|c|c|c|c|c|c|}
\hline & $\begin{array}{l}\text { Age at } \\
\text { electro- } \\
\text { encephalography } \\
\text { (years) }\end{array}$ & $\begin{array}{l}\text { Age at' } \\
\text { diagnosis (years) }\end{array}$ & $\begin{array}{l}\text { Duration of } \\
\text { diabetes (years) }\end{array}$ & $\begin{array}{l}\text { Daily insulin } \\
\text { dose (U/kg) }\end{array}$ & $\begin{array}{l}H b A, \\
\text { concentration } \\
(\%)\end{array}$ \\
\hline $\begin{array}{l}\text { Diabetics with } \\
\text { severe hypoglycaemia }\end{array}$ & $9.7(0.8)$ & $5.0(0.7)$ & $4.9(0.6)$ & $0.9(0 \cdot 1)$ & $11 \cdot 3(0 \cdot 2)$ \\
\hline $\begin{array}{l}\text { Diabetics without } \\
\text { severe hypoglycaemia } \\
\text { p Value }\end{array}$ & $\begin{array}{l}12.3(0.7) \\
<0.02\end{array}$ & $\begin{array}{l}7 \cdot 2(0.6) \\
>0.5\end{array}$ & $\begin{array}{l}5 \cdot 1(0 \cdot 5) \\
>0 \cdot 5\end{array}$ & $\begin{array}{l}0.9(0 \cdot 1) \\
>0 \cdot 5\end{array}$ & $\underset{>0.5}{11.4}(0.2)$ \\
\hline
\end{tabular}




\section{Discussion}

The results of the present study confirm previous data showing that diabetic children have an increased incidence of electroencephalographic abnormalities compared with the general population. ${ }^{3-8}$ Our incidence is in the range reported by others, ${ }^{3-6}$ but comparison is difficult due to the different electroencephalographic criteria used by different authors. As our results have shown, the incidence was high (49\%) when all abnormalities including 'borderline' changes were considered, but was considerably lower $(26 \%)$ if only grade 3 to 5 abnormalities were regarded as abnormal.

The aetiology and pathogenesis of these abnormalities is not entirely clear. Several studies have tried to analyse the role of metabolic control, microvascular and other late complications, and previous hypoglycaemia. Some earlier ${ }^{3-4}$ and some more recent $^{58}$ studies suggested a positive correlation between electroencephalographic abnormalities and the degree of metabolic control. The criteria for metabolic control in these reports, however, were somewhat arbitrary; the terms 'good', 'moderate', 'insufficient', and 'poor' were used and the grouping of diabetic children according to these criteria was based on unreliable record books, sporadic measurements of glycosuria, ketonuria, and blood glucose concentrations. Only the advent of $\mathrm{HbA}_{1}$ measurements has given us the possibility for the objective long term assessment of metabolic control, and our study is the first to report on the association between metabolic control (measured by $\mathrm{HbA}_{1}$ ) and electroencephalographic abnormalities. We found no correlation between electroencephalographic abnormalities and metabolic control or duration of diabetes. This finding suggests that chronic hyperglycaemia alone is probably not a major factor in causing these abnormalities, although there was not a wide variation of the $\mathrm{HbA}_{1}$ values and diabetes was of comparatively short duration in the diabetic children studied.

Our results clearly show that electroencephalographic abnormalities were associated with the frequency of previous severe attacks of hypoglycaemia. $^{3} 57$ The vast majority $(80 \%)$ of children with severe hypoglycaemia had some degree of electroencephalographic abnormalities, only one of eight children with repeated severe hypoglycaemia had a normal electroencephalogram, and every child with hypoglycaemic convulsions had some abnormality $(n=11)$. These findings, however, do not prove a causal relationship between hypoglycaemia and electroencephalographic abnormalities. As electroencephalographic recordings were not made at the time of diagnosis of the diabetes, it is possible that some of the diabetic children had pre-existing electroencephalographic abnormalities and these children were more likely to have a seizure during an episode of hypoglycaemia. The electroencephalographic abnormalities in hypoglycaemic children seems to be permanent lesions still detectable after a mean observation period of 15 months.

Because severe hypoglycaemia seems to be associated with electroencephalographic abnormalities in diabetic children, we have also estimated its incidence in our diabetic population. The overall incidence of severe hypoglycaemia in our cohort of patients was 0.12 episodes/patient year, which is in accordance with recently published data on conventionally treated diabetic patients. ${ }^{10}$ With the knowledge on the incidence of severe hypoglycaemia and electroencephalographic patterns, one may hypothesise on the influence of hypoglycaemia on the electroencephalogram. Even with the modest incidence of 0.12 hypoglycaemic episodes/year, a diabetic child is likely to have between five and eight severe episodes in his or her lifetime. The cumulative effects of these may well be not negligible.

Finally, we have tried to identify 'hypoglycaemia risk factors', and have shown that hypoglycaemia was not related to daily insulin dose, age at diagnosis, or duration of diabetes, but the mean age of the 'hypoglycaemic group' was significantly lower.

Although hypoglycaemia seems to be the major factor associated with electroencephalographic abnormalities there must have been other risk factors as well, as the incidence of abnormalities in the 'non-hypoglycaemic' group was also higher than in the general population. These possible risk factors cannot be identified in our study. It is possible that some children already had subclinical microvascular lesions or that there is indeed a 'primary diabetic encephalopathy' as suggested by Eeg-Olofson and Petersen. ${ }^{3}$

The clinical relevance of these abnormalities is not known. As we mentioned earlier, none of the children studied had neurological symptoms or neurological abnormalities. In spite of that, serial electroencephalographic recordings seem to be warranted in diabetic children with previous severe hypoglycaemic episodes. Finally, young diabetic children with documented electroencephalographic abnormalities are possibly at an increased risk of brain injury during recurrent hypoglycaemic states, and further studies are needed to clarify whether electroencephalographic recording could be a useful way of selecting patients for intensified insulin treatment to prevent the deleterious effects of hypoglycaemia. 
We are grateful to Mrs A Tölösi for technical assistance.

\section{References}

1 Marks V, Rose FC. Hypoglycaemia. Oxford: Blackwell, 1981.

${ }^{2}$ Harworth J, Coodin FJ. Idiopathic spontaneous hypoglycaemia in children. Report of seven cases and review of the literature. Pediatrics 1960;25:748-65.

${ }^{3}$ Eeg-Olofson O, Petersen I. Childhood diabetic neuropathy. A clinical and neurophysiological study. Acta Paediatr Scand 1966;55:163-76.

${ }^{4}$ Eysold R. Cerebrale Störungen bei Diabetes mellitus und elektroencephalographische Untersuchungen bei diabetischen Kindern. Monatsschr Kinderheilkd 1966;114:94-101.

${ }^{5}$ Haumont D, Dorchy H, Pelc S. EEG abnormalities in diabetic children. Influence of hypoglycaemia and vascular complications. Clin Pediatr 1979;18:750-3.

- Gilhaus KH, Daweke H, Lülsdorf HG, Sachsse B. EEGVeränderungen bei diabetischen Kindern. Dtsch Med Wochenschr 1973;98:1449-54.
${ }^{7}$ Schlanck H, Palm D, Jochnus I. Der Einfluss rezidivierender Hypoglykämien auf des EEG des diabetischen Kindes. Monatsschr Kinderheilkd 1969;117:251-2.

${ }^{8}$ Tsalikian E, Becker DJ, Crumrine PK, Daneman D, Drash AL. Electroencephalographic changes in diabetic ketosis in children with newly and previously diagnosed insulin-dependent diabetes mellitus. J Pediatr 1981;98:355-9.

9 Tsuboi T. Seizures of childhood. Acta Neurol Scand 1986;74 (suppl 110):192-8.

${ }^{10}$ Feldt-Rasmussen B, Mathiessen ER, Deckert T. Effect of two years of strict metabolic control on progression of incipient nephropathy in insulin-dependent diabetes. Lancet 1986;ii: $1300-4$.

Correspondence to Dr G Soltész, Department of Paediatrics, University of Pécs, Pécs, H-7623 Hungary.

Accepted 24 January 1989 